\title{
Enzyme replacement therapy reduces the risk for wheelchair dependency in adult Pompe patients
}

\author{
Jan C. van der Meijden ${ }^{1}$, Michelle E. Kruijshaar ${ }^{1}$, Dimitris Rizopoulos², Pieter A. van Doorn ${ }^{1,3}$,
}

Nadine A. M. E. van der Beek ${ }^{1,3}$ and Ans T. van der Ploeg ${ }^{1 *}$

\begin{abstract}
Background: Pompe disease is a rare metabolic myopathy. In adult patients, progressive weakness of limb-girdle and respiratory muscles often leads to wheelchair and respirator dependency. Clinical studies have shown enzyme replacement therapy (ERT) to positively affect motor and respiratory outcomes. Here we investigate whether ERT reduces patients' risk of needing a wheelchair or respirator.

Methods: Data were collected as part of a prospective international survey, the IPA/Erasmus MC Pompe survey, which was conducted annually between 2002 and 2016. We excluded patients who were already using a wheelchair or respirator, those under 18 at survey entry, and those who had missing information. Time-dependent Cox proportional hazard models were used.

Results: The inclusion criteria for analyzing the risk of wheelchair use were met by 189 patients (median age 47 years; range 18-75). During follow-up, 126 (67\%) started ERT. Over 1120 person-years of follow-up (median 5 years), 46 became wheelchair dependent, 16 of whom used ERT. After adjustment for disease duration, sex and country, ERT reduced the risk for wheelchair use (HR 0.36; 95\% Cl 0.17-0.75). For analyses of respirator use, 177 patients met the inclusion criteria (median age 46 years; range 18-73). Over 1190 person-years of follow-up (median 6 years), 125 patients (71\%) were treated and 48 started respiratory support, 28 of whom received ERT. We found no association between ERT and the risk for respirator use (HR 1.23; 95\% Cl 0.61-2.47).
\end{abstract}

Conclusions: Our study found that ERT reduced the risk for wheelchair dependency. We could not demonstrate an effect on respiratory support.

Keywords: Pompe disease, Enzyme replacement therapy, ERT, Wheelchair, Respiratory support, Hazard ratio

\section{Background}

Pompe disease is an autosomal recessive metabolic myopathy for which enzyme replacement therapy (ERT) with alglucosidase alfa has been available since 2006 [1, 2]. In adults, the disease is characterized by progressive limbgirdle and respiratory muscle weakness. In most cases, this ultimately leads to the use of a wheelchair and/or respiratory support [3, 4]. Wheelchair dependency and the use of respiratory support considerably impact a patient's ability to participate in daily life activities, and reduce quality of

\footnotetext{
* Correspondence: a.vanderploeg@erasmusmc.nl

${ }^{1}$ Center for Lysosomal and Metabolic Diseases, Erasmus MC University Medical Center, PO Box 2040, 3000, CA, Rotterdam, the Netherlands Full list of author information is available at the end of the article
}

life $[5,6]$. It should therefore be an important treatment goal to prevent the disease from progressing to the point that a patient becomes dependent on these aids.

Many studies have evaluated the effects of ERT in adult patients with Pompe disease. While these have shown that ERT has a positive effect on motor function and/or lung function [7-15], its effect on wheelchair dependency and respiratory support has been reported only in a few cases.

Together with the International Pompe Association (IPA), our center has systematically collected data on patients with Pompe disease since 2002, well before the approval of ERT. This IPA/Erasmus MC Pompe survey has consistently followed a large international cohort of

(c) The Author(s). 2018 Open Access This article is distributed under the terms of the Creative Commons Attribution 4.0 International License (http://creativecommons.org/licenses/by/4.0/), which permits unrestricted use, distribution, and reproduction in any medium, provided you give appropriate credit to the original author(s) and the source, provide a link to the Creative Commons license, and indicate if changes were made. The Creative Commons Public Domain Dedication waiver (http://creativecommons.org/publicdomain/zero/1.0/) applies to the data made available in this article, unless otherwise stated. 
patients over many years, both before and during ERT. Earlier findings from the survey include the demonstration of a positive effect of ERT on survival [16]. Using data from this survey, we investigated whether ERT reduces the risk that a patient will need a wheelchair or respiratory support.

\section{Methods}

\section{Patients}

A detailed description of the survey's design has been published previously [16]. Since 2002, patients have been recruited through national patient organizations in Canada, Germany, France, the Netherlands, the United Kingdom and the United States. Recruitment was independent of patients' disease severity. All patients have provided informed consent.

Annual survey questions included items on the use of a wheelchair and respiratory support. Disease duration was calculated as the number of years since diagnosis. In our analyses we included all questionnaires completed before July 2016.

The current study included patients aged 18 years and above at inclusion in the survey. Patients who already used a wheelchair or respiratory support at survey entry (i.e. who had already had the "event") were excluded from the analyses, as were those who had completed the survey only once (no follow-up) or had incomplete information on the events or disease duration.

\section{Statistical analysis}

Time-dependent Cox proportional hazard models were used to calculate the effect of ERT on the risk of using a wheelchair or respiratory support. Models were developed separately for both outcomes.

Age was used as the time scale of the analysis, each patient being followed from the age at inclusion in the survey, until the date of last follow-up (censoring), or until becoming wheelchair or ventilator dependent. ERT was assessed as a time-dependent variable that switched from 0 to 1 when patients started treatment. This approach allowed patients' to contribute both treated and untreated person-years of follow-up to the analyses. The following covariates were chosen a priori: disease duration, gender and country of residence. Like ERT, disease duration was included as a time-dependent covariate, updating when patients started treatment.

Results are presented as hazard ratios (HRs) with 95\% confidence intervals (CIs). The proportional hazards assumption was checked by plotting scaled Shoenfeld residuals and correlating them with the Kaplan Meier estimate of the survival function.

Since both analyses originate from the same population, we used the Holm method to correct for multiple testing [17]. Please note that the two populations overlap, but are not entirely the same since some of the exclusions depend on whether one is assessing wheelchair or ventilator dependency.

Statistical tests were performed using $\mathrm{R}$ version 3.3.1 including the survival package $[18,19]$. A $p$-value $<0.05$ was considered significant.

\section{Results}

Overall, 458 patients participated in the IPA/Erasmus MC Pompe survey between 2002 and July 2016. The inclusion flow-chart in Fig. 1 shows that 189 patients were eligible for analysis of the effect of ERT on wheelchair dependency and that 177 were eligible for analysis of respiratory support (131 patients were in both analyses). 125 patients (27\%) were excluded as they already used a wheelchair at survey entry; 150 (33\%) were excluded because they already required respiratory support.

Table 1 compares the baseline characteristics of patients included in the two analyses with those of all patients participating in the IPA/Erasmus MC survey. Overall, patients who participated in the survey $(n=458)$ were equally distributed between the sexes, and entered the survey at a median age of 47 years. Seventy percent started ERT at some point during their follow-up. Patients who fulfilled the inclusion criteria for our analyses had a shorter disease duration compared to those who were excluded from the analyses (both $p<0.001$ ). This might be explained by the fact that patients who required a wheelchair or ventilator at survey entry had to be excluded from the analysis. Patients included in the analyses were also more frequently from the Netherlands (both $p<0.001$ ). Patients in the ventilator analysis were more frequently female than those excluded from this analysis $(p<0.001)$.

Table 2 shows the results of the time-dependent Cox proportional hazard regression models. A total of 1120 person-years of follow-up were available for our analysis of the effect of ERT on wheelchair use (median followup 5 years, Table 1). Sixteen events occurred over 652 treated-person years and 30 events over 468 untreatedperson years. After adjustment for disease duration at survey entry and at start of ERT, and also for sex and country, ERT significantly reduced the risk of becoming wheelchair dependent (hazard ratio of 0.36 ; CI $0.17-$ 0.75 , Table 2). In other words, at any point during follow-up, a treated patient had a $64 \%$ lower risk for becoming wheelchair dependent than an untreated patient. Disease duration was an important predictor of becoming wheelchair dependent: the risk for becoming wheelchair dependent was over three times higher in those whose disease duration was over 10 years than in those with less than 5 years. Country of residence was also significantly associated with the risk for wheelchair use, with patients 


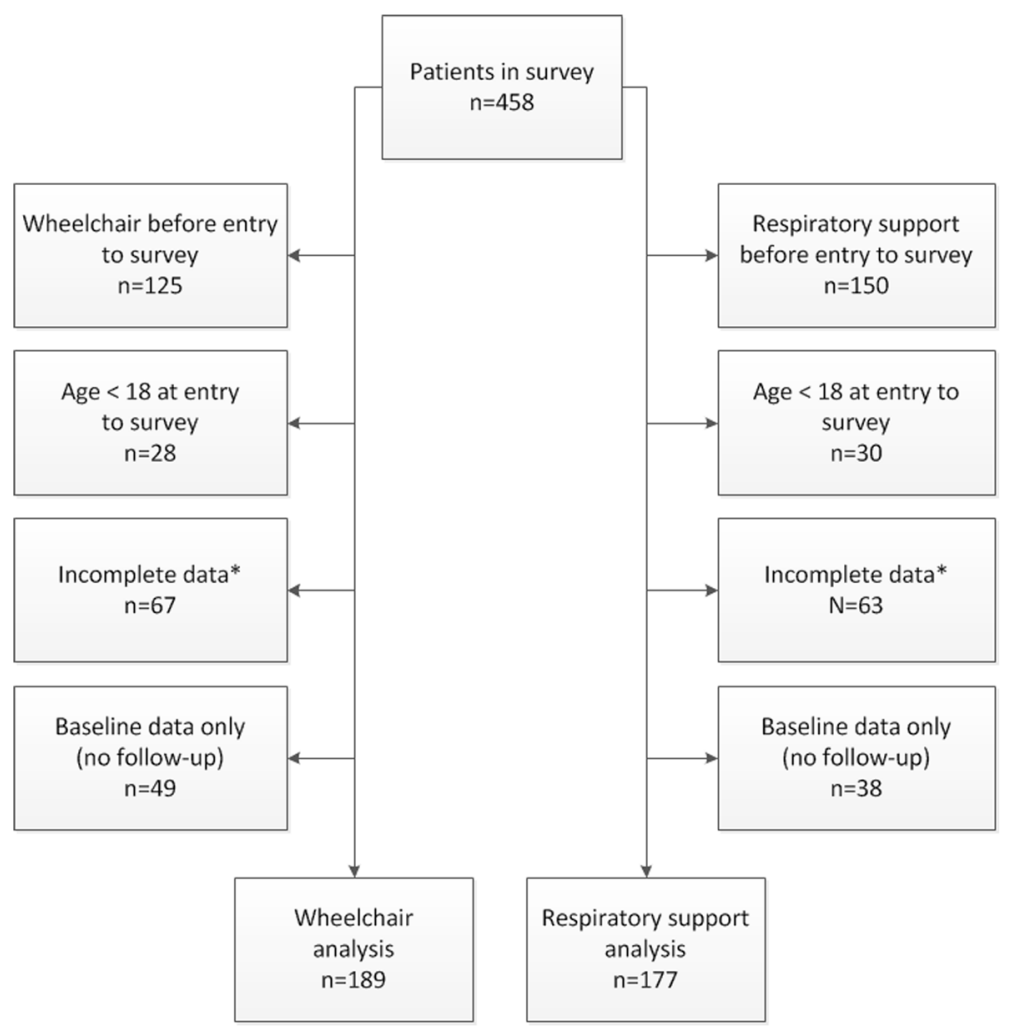

Fig. 1 Inclusion flowchart. *Data was incomplete if either the age at which the event occurred or the disease duration was unknown

Table 1 Characteristics of patients participating in the analysis of the effect of ERT on the use of a wheelchair and respiratory support, and of all patients included in the IPA/Erasmus MC Pompe survey

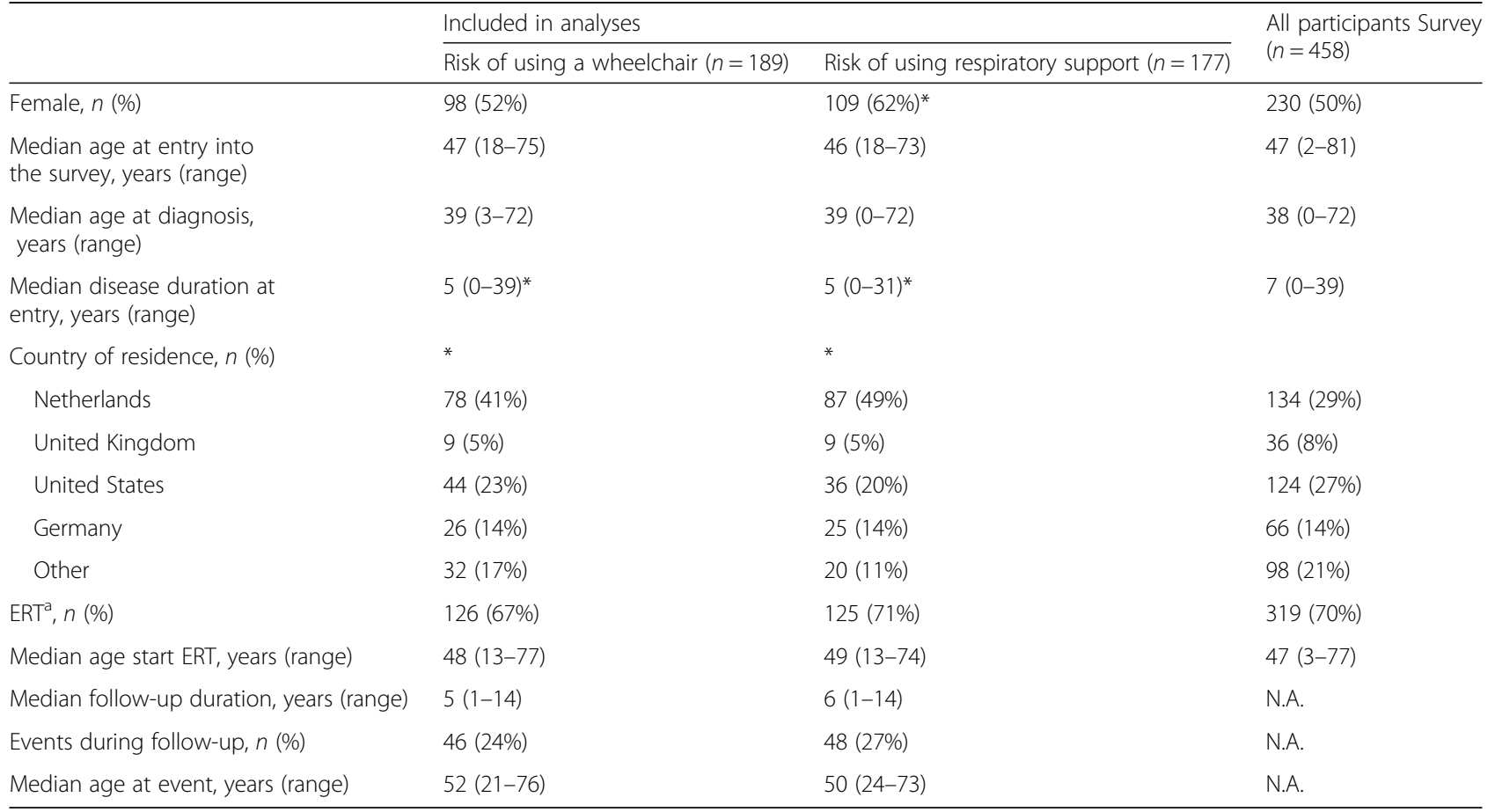

amost patients started ERT at some point during their follow-up; 57 patients in the analyses of wheelchair use and 37 in the analyses of use of respiratory support were already receiving ERT at survey entry. *: the median/proportion was significantly different $(p<0.05)$ from the median/proportion in the patients who were excluded from this analysis 
Table 2 Multivariate time-dependent Cox regression analysis of wheelchair use (A) and the need for respiratory support (B)

\begin{tabular}{|c|c|c|c|c|c|}
\hline & Events & Person-years & $\mathrm{HR}$ & $95 \% \mathrm{Cl}$ & $p$-value \\
\hline \multicolumn{6}{|l|}{ A. Wheelchair use } \\
\hline \multicolumn{6}{|l|}{ Treatment $^{\mathrm{a}}$} \\
\hline Untreated (ref) & 30 & 468 & & & \\
\hline ERT & 16 & 652 & 0.36 & $(0.17-0.75)$ & 0.004 \\
\hline \multicolumn{6}{|l|}{ Disease duration ${ }^{\mathrm{a}}$} \\
\hline$<5$ years (ref) & 10 & 464 & & & \\
\hline $5-10$ years & 10 & 332 & 1.19 & $(0.41-3.48)$ & 1 \\
\hline$>10$ years & 26 & 324 & 3.87 & $(1.55-9.61)$ & 0.002 \\
\hline \multicolumn{6}{|l|}{ Sex } \\
\hline Male (ref) & 17 & 583 & & & \\
\hline Female & 29 & 537 & 1.80 & $(0.88-3.69)$ & 0.13 \\
\hline \multicolumn{6}{|l|}{ Country of residence } \\
\hline Netherlands (ref) & 13 & 531 & & & \\
\hline Germany & 9 & 173 & 1.19 & $(0.41-3.47)$ & 1 \\
\hline US & 12 & 214 & 1.95 & $(0.73-5.22)$ & 0.13 \\
\hline Other & 12 & 202 & 2.99 & $(1.17-7.67)$ & 0.018 \\
\hline \multicolumn{6}{|l|}{ B. Respiratory support } \\
\hline \multicolumn{6}{|l|}{ Treatment $^{\mathrm{a}}$} \\
\hline Non-use (ref) & 20 & 529 & & & \\
\hline ERT & 28 & 661 & 1.23 & $(0.61-2.47)$ & 0.51 \\
\hline \multicolumn{6}{|l|}{ Disease duration ${ }^{a}$} \\
\hline$<5$ years (ref) & 11 & 430 & & & \\
\hline $5-10$ years & 12 & 319 & 1.12 & $(0.42-3.02)$ & 1 \\
\hline$>10$ years & 25 & 441 & 2.13 & $(0.89-5.09)$ & 0.051 \\
\hline \multicolumn{6}{|l|}{ Sex } \\
\hline Male (ref) & 21 & 420 & & & \\
\hline Female & 27 & 770 & 0.67 & $(0.34-1.32)$ & 0.18 \\
\hline \multicolumn{6}{|l|}{ Country of residence } \\
\hline Netherlands (ref) & 18 & 599 & & & \\
\hline Germany & 9 & 189 & 1.28 & $(0.48-3.38)$ & 1 \\
\hline US & 13 & 213 & 2.22 & $(0.90-5.49)$ & 0.10 \\
\hline Other & 8 & 189 & 1.37 & $(0.52-3.62)$ & 0.46 \\
\hline
\end{tabular}

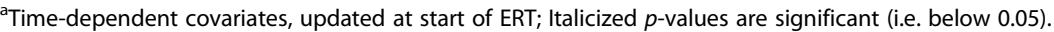

from countries other than the Netherlands, Germany, and the US having a higher risk of using a wheelchair than those from the Netherlands.

For the analysis of use of respiratory support, 1190 person-years were accumulated (median follow-up 6 years, Table 1). Over 661 treated person-years, 28 patients started using respiratory support, compared to 20 patients over 529 untreated person-years. We detected no association between ERT and the risk for starting respiratory support (HR 1.23; 95\%CI 0.61-2.47). Longer disease duration again tended to increase the risk for starting respiratory support, while no significant difference was detected for sex or country of residence.

\section{Discussion}

This is the first study to provide evidence that ERT with Alglucosidase alfa reduces the risk that adult patients with Pompe disease will become wheelchair dependent. Using data from an international cohort of almost 200 adult patients, we show that, at any point in time, a patient who received ERT had a $64 \%$ smaller probability of becoming wheelchair dependent than an untreated patient. With 
regard to the risk for starting respiratory support, no differences could be detected.

To patients, ambulatory and respiratory status are relevant outcomes that have a substantial impact on quality of life $[6,20]$. As sometimes decades may pass between a patient's first symptoms and their becoming ventilator or wheelchair dependent, a large cohort and long follow-up are required to study changes in these outcomes. Similarly, any study of the effect of treatment on these outcomes requires data that were obtained before and after start of this treatment. Our survey uniquely meets these requirements.

Since ambulation requires sufficient muscle strength and function, our finding that ERT reduces the risk of becoming wheelchair dependent is in line with studies reporting improvements in muscle strength and function [7-15]. With regard to our inability to demonstrate an effect of ERT on the risk for respiratory support, this may have been due to the smaller effect of ERT on respiratory muscles than on skeletal muscles, which has been reported in several earlier studies [7, 9-11, 13].

Our analyses were corrected for disease duration, country of residence and gender. Longer disease duration increased the risk for both wheelchair and respiratory support, which is in line with the progressive character of the disease, and was also concluded from earlier studies from the IPA/Erasmus MC Pompe survey and our clinical studies [21-23]. The risk of wheelchair use varied between country, potentially as a result of differences in healthcare systems or in diagnostic delays. Although the survey detected no differences between gender on the risk for wheelchair use and respiratory support, the fact that a larger proportion of men than women were already using respiratory support at inclusion in the survey suggests that there may be gender differences in lung function. This was also suggested by our earlier study in untreated adults, where the decline in lung function was faster in men [23]. More research is needed to elucidate these differences.

The IPA survey is an open cohort into which patients are continually included. It has been shown to be a good reflection of the clinical spectrum of adult patients with Pompe disease [20]. Some bias may have occurred as some patients will become lost to follow-up in such a long-term study. In addition to correcting for confounders, bias was further minimized in this study through the time dependent nature of the analysis, as the same patient could contribute to both the treated and untreated period.

The difference between being able to walk and needing a wheelchair is very tangible, and ERT's reduction of the risk for becoming wheelchair dependent is an important improvement. Nevertheless, a proportion of treated patients still become wheelchair dependent at some point in their life. Hence, while ERT shows positive clinical effects in adult patients with Pompe disease, we also conclude that there is still room for improvement.

\section{Conclusion}

ERT reduces the risk for wheelchair dependency in adult Pompe patients. Since ambulation provides independence, we believe this is of key importance to patients. An effect of ERT on the risk for respiratory support could not be demonstrated.

\section{Abbreviations \\ Cl: Confidence Interval; ERT: Enzyme replacement therapy; HR: Hazard Ratio; IPA: International Pompe Association}

\section{Acknowledgements}

The IPA/Erasmus MC Pompe survey was a joint initiative of the International Pompe Association (IPA) and Erasmus MC University Medical Center. We thank all patients for participating in the survey, Marylyn and Tiffany House, Ria Broekgaarden, Allan Muir, Thomas Schaller, Guy Ashford-Smith, Raymond Saich, Marsha Zimmerman, and Rineke Nelisse for their contributions to the organizational part of the study, and David Alexander for his critical reading of the manuscript.

\section{Funding}

Research on Pompe disease at Erasmus MC is financially supported by ZonMW - the Netherlands Organization for Health Research and Development [projectnumber 152001005], the Prinses Beatrix Fonds [projectnumber W.OR1321, W.OR15-10, W.OR16-07], TKI - Health Holland [projectnumber LSHM16008], Tex Net, SSWO [projectnumber S17-32], Metakids [projectnumber 2016-063],

"Conselho Nacional de Desenvolvimento Científico e Tecnológico" - the National Counsel of Technological and Scientific Development, Brasil (PI), Colciencias and Sanofi Genzyme.

Availability of data and materials

For reasons of privacy, the dataset is not publicly available.

\section{Authors' contributions}

JvdM: participated in the design of the study, data analyses and interpretation and drafted the manuscript. MK participated in the design of the study, data analysis and interpretation and contributed to the drafting of the manuscript; $D R$, participated in the data analysis. AvdP conceived the study, participated in its design and interpretation and coordinated the drafting of the manuscript. All authors were involved in the interpretation of the data, revised the manuscript and read and approved the final manuscript.

\section{Ethics approval and consent to participate}

All procedures followed were in accordance with the ethical standards of the responsible committee on human experimentation (institutional and national) and with the Helsinki Declaration of 1975, as revised in 2000. All patients and/or their parents provided informed consent. The medical ethical committee of the Erasmus MC approved the study protocol.

\section{Competing interests}

AvdP has provided consultancy services to various industries, including Sanofi Genzyme who manufacture myozyme. JvdM, MK, DR, NvdB and PvD declare that they have no conflict of interest.

\section{Publisher's Note}

Springer Nature remains neutral with regard to jurisdictional claims in published maps and institutional affiliations.

\section{Author details}

${ }^{1}$ Center for Lysosomal and Metabolic Diseases, Erasmus MC University Medical Center, PO Box 2040, 3000, CA, Rotterdam, the Netherlands. ${ }^{2}$ Department of Biostatistics, Erasmus MC University Medical Center, Rotterdam, the Netherlands. ${ }^{3}$ Department of Neurology, Erasmus MC University Medical Center, Rotterdam, the Netherlands. 
Received: 29 January 2018 Accepted: 9 May 2018

Published online: 22 May 2018

\section{References}

1. Hirschhorn R, Reusser AJ. Glycogen storage disease type Il: acid alphaglucosidase (acid maltase) deficiency. In: Scriver CR, Beaudet AL, Sly WS, Valle D, editors. The metabolic and molecular bases of inherited disease. New York: McGraw-Hill; 2001. p. 3389-420.

2. Engel AG, Hirschhorn R, Huie ML. Acid Maltase Deficiency. In: Engel AG, editor. Myology. New York: McGraw-Hill; 2004. p. 1559-86.

3. Van der Beek NA, Hagemans ML, Reuser AJ, Hop WC, Van der Ploeg AT, Van Doorn PA, et al. Rate of disease progression during long-term follow-up of patients with late-onset Pompe disease. Neuromuscul Disord. 2009;19:113-7.

4. van der Ploeg AT, Reuser AJ. Pompe's disease. Lancet. 2008;372:1342-53.

5. Hagemans ML, Janssens AC, Winkel LP, Sieradzan KA, Reuser AJ, Van Doorn $P A$, et al. Late-onset Pompe disease primarily affects quality of life in physical health domains. Neurology. 2004;63:1688-92.

6. Hagemans ML, Laforet P, Hop WJ, Merkies IS, Van Doorn PA, Reuser AJ, et al. Impact of late-onset Pompe disease on participation in daily life activities: evaluation of the Rotterdam handicap scale. Neuromuscul Disord. 2007;17: 537-43.

7. Anderson LJ, Henley W, Wyatt KM, Nikolaou V, Waldek S, Hughes DA, et al. Effectiveness of enzyme replacement therapy in adults with late-onset Pompe disease: results from the NCS-LSD cohort study. J Inherit Metab Dis. 2014;37:945-52.

8. Angelini C, Semplicini C, Ravaglia S, Bembi B, Servidei S, Pegoraro E, et al. Observational clinical study in juvenile-adult glycogenosis type 2 patients undergoing enzyme replacement therapy for up to 4 years. J Neurol. 2012; 259:952-8.

9. de Vries JM, van der Beek NA, Hop WC, Karstens FP, Wokke JH, de Visser M, et al. Effect of enzyme therapy and prognostic factors in 69 adults with Pompe disease: an open-label single-center study. Orphanet J Rare Dis. 2012;7:73.

10. Regnery C, Kornblum C, Hanisch F, Vielhaber S, Strigl-Pill N, Grunert B, et al. 36 months observational clinical study of 38 adult Pompe disease patients under alglucosidase alfa enzyme replacement therapy. J Inherit Metab Dis. 2012;35:837-45.

11. van der Ploeg AT, Barohn R, Carlson L, Charrow J, Clemens PR, Hopkin RJ, et al. Open-label extension study following the late-onset treatment study (LOTS) of alglucosidase alfa. Mol Genet Metab. 2012;107:456-61.

12. van der Ploeg AT, Clemens PR, Corzo D, Escolar DM, Florence J, Groeneveld $\mathrm{GJ}$, et al. A randomized study of alglucosidase alfa in late-onset Pompe's disease. N Engl J Med. 2010;362:1396-406.

13. Strothotte S, Strigl-Pill N, Grunert B, Kornblum C, Eger K, Wessig C, et al. Enzyme replacement therapy with alglucosidase alfa in 44 patients with late-onset glycogen storage disease type 2: 12-month results of an observational clinical trial. J Neurol. 2010;257:91-7.

14. van der Ploeg AT, Kruijshaar ME, Toscano A, Laforet P, Angelini C, Lachmann RH, et al. European consensus for starting and stopping enzyme replacement therapy in adult patients with Pompe disease: a 10-year experience. Eur J Neurol. 2017;24:768-e31.

15. Stepien KM, Hendriksz CJ, Roberts M, Sharma R. Observational clinical study of 22 adult-onset Pompe disease patients undergoing enzyme replacement therapy over 5years. Mol Genet Metab. 2016;117:413-8.

16. van der Meijden JC, Gungor D, Kruijshaar ME, Muir AD, Broekgaarden HA, van der Ploeg AT. Ten years of the international Pompe survey: patient reported outcomes as a reliable tool for studying treated and untreated children and adults with non-classic Pompe disease. J Inherit Metab Dis. 2015;38:495-503.

17. Holm S. A simple sequentially Rejective multiple test procedure. Scand J Stat. 1979;6:65-70.

18. Therneau TM, Grambsch PM. Modeling survival data: extending the cox model. New York: Springer; 2000.

19. R Core Team R. A Language and Environment for Statistical Computing. Vienna: R Foundation for Statistical. Computing; 2015.

20. Gungor D, Kruijshaar ME, Plug I, Rizopoulos D, Kanters TA, Wens SC, et al. Quality of life and participation in daily life of adults with Pompe disease receiving enzyme replacement therapy: 10 years of international follow-up. J Inherit Metab Dis. 2016;39:253-60.

21. Hagemans ML, Winkel LP, Hop WC, Reuser AJ, Van Doorn PA, Van der Ploeg AT. Disease severity in children and adults with Pompe disease related to age and disease duration. Neurology. 2005;64:2139-41.
22. van der Beek NA, de Vries JM, Hagemans ML, Hop WC, Kroos MA, Wokke $\mathrm{JH}$, et al. Clinical features and predictors for disease natural progression in adults with Pompe disease: a nationwide prospective observational study. Orphanet J Rare Dis. 2012;7:88.

23. van der Beek NA, van Capelle Cl, van der Velden-van Etten Kl, Hop WC, van den Berg B, Reuser AJ, et al. Rate of progression and predictive factors for pulmonary outcome in children and adults with Pompe disease. Mol Genet Metab. 2011;104:129-36.

\section{Ready to submit your research? Choose BMC and benefit from:}

- fast, convenient online submission

- thorough peer review by experienced researchers in your field

- rapid publication on acceptance

- support for research data, including large and complex data types

- gold Open Access which fosters wider collaboration and increased citations

- maximum visibility for your research: over $100 \mathrm{M}$ website views per year

At BMC, research is always in progress.

Learn more biomedcentral.com/submissions 